\title{
COMPARAÇÃO ENTRE SEMENTES DE TRIGO PRODUZIDAS NO MÉXICO E NO BRASIL ${ }^{1}$
}

\author{
AROLDO G. LINHARES ${ }^{2}$ \\ J. L. NEDEL ${ }^{2}$
}

Revista Brasileira de Sementes, vol. 04, n³, p.19-25, 1982

RESUMO. Sementes de trigo produzidas no México (Vale do Yaqui, Sonora) e no Brasil (Passo Fundo, RS, e Brasília, DF) foram comparadas, através de ensaio de campo, para avaliação da influência da origem. Foram empregadas as cultivares brasileiras CNT 7, CNT 8, CNT 10, Nobre e IAC 5-Maringá (Maringá), sendo que a origem Brasília participou apenas com a cultivar Maringá. Utilizou-se delineamento em blocos ao acaso com onze tratamentos em quatro repetições. As sementes foram tratadas com o fungicida Benlate $\mathrm{T}$ e o ensaio recebeu aplicações de fungicidas e inseticida para controle de doenças e pragas da parte aérea. As cultivares CNT 7, Nobre e Maringá tiveram seus rendimentos prejudicados por geada. A avaliação de peso seco de plântulas apresentou, para as cultivares Nobre e Maringá, superioridade da semente produzida no México. Nos demais casos e para as avaliações de stand, número de espigas por metro quadrado e rendimento de grãos não se observou superioridade da semente produzida no México em comparação com a produzida no Brasil.

Termos para indexação: origem, semente, trigo, efeitos, stand, matéria seca, rendimento

\section{EVALUATION OF WHEAT SEEDS PRODUCED IN MÉXICO AND IN BRAZIL}

ABSTRACT. In order to evaluate the effect of source, wheat seeds produced in México (Yaqui Valley, Sonora) and in Brazil (Passo Fundo-RS and Brasília-DF) were compared in a field trial. Brazilian cultivars CNT 7, CNT 8, CNT 10, Nobre, and 1AC 5-Maringã (Maringá) were used, being that Brasília origin took part with cultivar Maringá only. A randomized blocks design with 11 treatments in four replications was used. Seeds were treated with Benlate $T$ and the trial was sprayed with fungicides and insecticides for controlling above-ground diseases and pests. Cultivars CNT 7, Nobre, and Maringá had their yields reduced by frost occurrence. Dry weight of seedlings was higher for cultivars Nobre and Maringá, for seed produced in México. In the remaining instances and in the evaluations of stand, number of spikes per square meter, and grain yield, no superiority was observed in seed produced in México as compared to those produced in Brazil.

\footnotetext{
${ }^{1}$ Trabalho apresentado no II Congresso Brasileiro de Sementes, Recife, PE, 21 a 25.09.1981. Recebido para publicação em 25.09.1981

2 Engs. Agrs., Pesquisadores do Centro Nacional de Pesquisa de Trigo EMBRAPA, Caixa Postal 569, CEP 99.100 - Passo Fundo, RS
} 
Index terms: source, wheat, seed, stand, dry weight, yield.

\section{INTRODUÇÃO}

A utilização no Brasil de sementes de trigo produzidas no México levantou a questão, em alguns casos, de uma suposta superioridade da semente mexicana sobre a semente de mesma cultivar produzida no Brasil.

No campo de melhoramento do Centro Nacional de Pesquisa de Trigo (CNPT), em 1976, linhas semeadas lado a lado, com sementes produzidas no México e em Passo Fundo, aparentemente mostravam uma superioridade das primeiras em relação às segundas, quanto ao desenvolvimento inicial de plantas, para diversas cultivares observadas. Também ensaios instalados no CNPT em 1977 e 1978, não concluídos por problemas adversos, indicavam visualmente um maior desenvolvimento inicial para os tratamentos correspondentes à semente produzida no México, em comparação com a semente local. Em experimentos conduzidos no Paraná, nos quais a cultivar INIA F66 participou através de semente produzida no México e de produção local, a primeira origem apresentou produtividade significativamente superior em todos os locais testados. Foi concluído que o vigor e, possivelmente, o tratamento fungicida da semente estariam influindo nesse comportamento (Organização das Cooperativas do Estado do Paraná - OCEPAR, 1976).

Os fatores determinantes de diferenças, quando ocorrem, devido à origem da semente não estão bem determinados e têm variado para diferentes autores.

Assim, enquanto McNeal e outros (1960) encontraram pequeno efeito no rendimento, para quatro diferentes origens de semente de trigo variando quanto ao teor da proteína e peso volumétrico, Quinby e outros (1962) obtiveram diferenças significativas em produção devido às origens da semente em dois dos três anos estudados. Os últimos autores compararam oito diferentes fontes de produção em três locais de ensaio e atribuíram a diferença de comportamento ao ambiente durante a formação da semente, além de causas fisiológicas não conhecidas.

No Canadá, em trabalho com cevada, Sterling e outros (1977) verificaram que o tratamento da semente com fungicidas reduziu as diferenças em rendimento devido às diferentes origens de produção.

O presente trabalho teve como finalidade procurar obter confirmação, para mais de uma cultivar, quanto às diferenças de comportamento observadas entre sementes de trigo produzidas no Brasil e no México.

\section{MATERIAL E MÉTODOS}

Em novembro de 1979 foram colhidas no CNPT, em Passo Fundo, Rio Grande do Sul, sementes das cultivares CNT 7, CNT 8, CNT 10, IAC 5-Maringá (Maringá) e Nobre. Dessas, cerca de $1 \mathrm{~kg}$ de cada uma foram colocadas em câmara seca (aproximadamente $20^{\circ} \mathrm{C}$ e $40 \%$ de umidade relativa), enquanto que se separou quantidade suficiente para plantio subseqüente no México (Vale do Yaqui, Sonora) e em Brasilia-DF (CPAC-Planaltina).

O cultivo no México foi conduzido sob irrigação. O plantio de Brasília foi 
prejudicado por seca, sendo que apenas a cultivar Maringá produziu quantidade suficiente para o ensaio.

As sementes produzidas no México e em Brasília foram recebidas em maio de 1980, sendo colocadas na câmara seca para uniformização dos teores de umidade. Posteriormente, as amostras foram colocadas em estufa a $35^{\circ} \mathrm{C}$, até a superação da dormência das sementes do México e Brasília.

Teste de germinação e determinações efetuadas para caracterização das sementes apresentaram os valores apresentados na Tabela 1. Anteriormente ao teste de germinação as sementes foram tratadas com o fungicida Benlate $\mathrm{T}$, na dosagem de $0,2 \%$. Adotou-se este procedimento tendo em vista que em teste prévio de germinação as sementes de Brasília e de Passo Fundo apresentaram alta ocorrência de fungos, dificultando a avaliação.

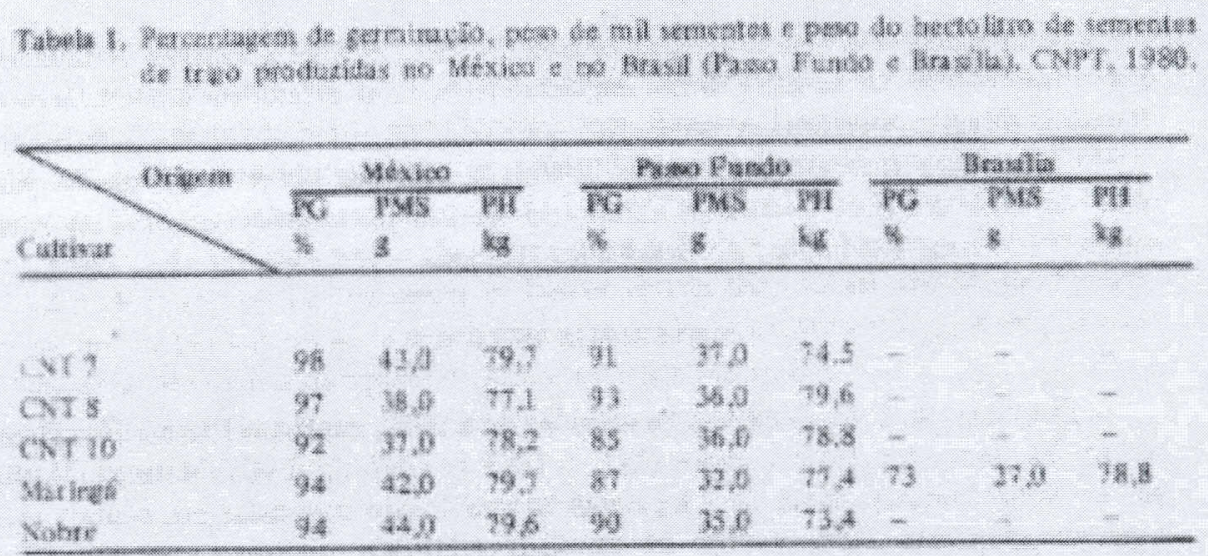

O ensaio de campo constou de um delineamento em blocos ao acaso, com quatro repetições. Os tratamentos, em número de onze, corresponderam às cultivares CNT 7, CNT 8, CNT 10, Nobre e Maringá, de origem do México e Passo Fundo, além da origem Brasília para a última cultivar.

As parcelas corresponderam a sete linhas de $5 \mathrm{~m}$ de comprimento com $0,20 \mathrm{~m}$ de espaçamento, sendo a área útil de $5 \mathrm{~m}^{2}$, relativa às cinco linhas centrais.

Com base no teste de germinação, corrigiu-se o número de sementes para obter-se 60 plantas por metro linear.

A semeadura foi efetuada em 23.6, sendo processada de forma manual. $O$ solo recebeu adubação de $13,2 \mathrm{~kg} \mathrm{~N}+61,6 \mathrm{~kg} \mathrm{P}_{2} \mathrm{O}_{5}+44 \mathrm{~kg} \mathrm{~K}_{2} \mathrm{O}$ por hectare, incorporados previamente à instalação do ensaio. Em 28.8 aplicou-se $20 \mathrm{~kg}$ de $\mathrm{N} / \mathrm{ha}$, na forma de uréia, em cobertura.

Para controle de doenças e pragas da parte aérea, foram efetuadas três aplicações de fungicidas e inseticidas recomendados.

Efetuou-se avaliação de stand 22 dias após a semeadura, contando-se o número de plântulas emergidas nas cinco linhas internas de cada parcela.

Para avaliação do peso seco da parte aérea foram coletadas 40 plântulas, cortadas rente ao solo, de cada primeira linha de borda. A pesagem foi feita após permanência do material em estufa a $70^{\circ} \mathrm{C}$, até obtenção de peso constante. Essa determinação foi efetuada 24 dias após plantio.

Para avaliação do número de espigas por metro quadrado foram contadas, por ocasião da colheita, todas as espigas da linha central de cada parcela.

A colheita para avaliação de rendimento de grãos foi efetuada de acordo 
com a maturação de cada cultivar. Os valores obtidos foram corrigidos para o teor de umidade de $11 \%$. O peso do hectolitro e o peso de mil sementes foram determinados após uniformização dos teores de umidade das sementes colhidas.

Os dados referentes à contagem de stand, peso seco de planta, número de espigas e rendimento foram submetidos à análise de variância, sendo a comparação entre médias feita pelo teste de Duncan a $5 \%$.

\section{RESULTADOS E DISCUSSÃO}

A análise da variância para os dados de contagem de stand, peso de matéria seca da parte aérea e rendimento mostraram valores de $F$ altamente significativos para tratamentos, enquanto para número de espigas não houve significância. Os coeficientes de variação obtidos foram baixos, conforme mostrados na Tabela 2.

\begin{tabular}{|c|c|c|c|c|c|c|c|c|c|}
\hline \multicolumn{10}{|c|}{ 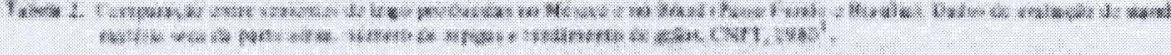 } \\
\hline 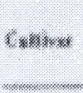 & $\min 2 \times n$ & 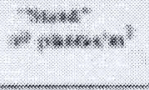 & \multicolumn{2}{|c|}{ 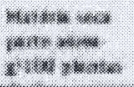 } & $\begin{array}{l}x+\infty \\
x^{2} \\
*\end{array}$ & \multicolumn{2}{|c|}{ 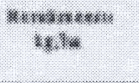 } & 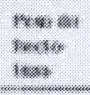 & 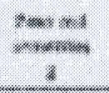 \\
\hline 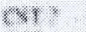 & 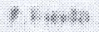 & 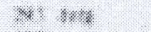 & $=:: 88$ & .8 .8 & 4. 3 & $3.16 \%$ & 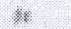 & 98 & 38 \\
\hline 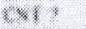 & 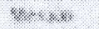 & $38: 8$ & $3 \%$ & 8,6 & 78: : & 2113 & 8 & 98 & (4) \\
\hline $1 * 1 ; 4$ & 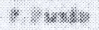 & $28 \times 3.8$ & 2.288 & is & 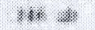 & 2.1848 & $\$:$ & 48 & $* 3$ \\
\hline$\% 8 \%:$ & 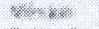 & 488 & $7: \frac{1 \pi}{x}$ & 84.4 & 3:\%: & 3814 & : & *. & $w$ \\
\hline $8 \% 18$ & 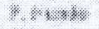 & 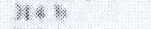 & 2.86 & x & $30: 8$ & 3.106 & \& & 4. & $x:$ \\
\hline 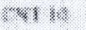 & $4: 3: x=2$ & $x: 9 k:$ & 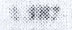 & \& & 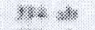 & 24.8 & *3: & 8. & 28 \\
\hline 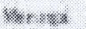 & 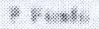 & $=48$ & $208 \%$ & 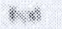 & 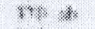 & 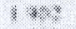 & (8. & $\%$ & 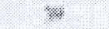 \\
\hline (6): is & $4 .: 2$. & $28: \quad 28$ & $2: 2: 2$. & 2. & $x: 2: 28$ & 3.48 & : & 4 & 18 \\
\hline 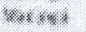 & $4: x::: x$ & $4 \%$ & $8: 8: 3$ & 48 & $34: 48$ & 13162 & si & 3 & 8 \\
\hline$* 8: 2$ & $8 * x: 3$ & 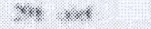 & 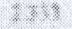 & 8 & 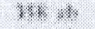 & 188 & 4 & 3 & 31 \\
\hline 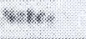 & $4: x: 0:$ & $4: 2$ & $2: 2:=8$ & 3 & $3: 4 \times 6$ & 4.818 & 8 & .3 & 4) \\
\hline c*s & & $=88$ & $48:$ & & $\% \%$ & 9818 & & & \\
\hline
\end{tabular}

Os dados de stand (Tabela 2) mostraram diferença entre origens apenas para a cultivar Maringá. Entretanto, o valor mais elevado apresentado pela semente obtida em Brasília foi muito superior ao esperado, podendo ser atribuído a sementes dormentes que, sob condições de campo, encontraram condições favoráveis para germinar.

$\mathrm{Na}$ comparação entre peso de matéria seca da parte aérea (Tabela 2), a semente das cultivares Nobre e Maringá oriunda do México foi superior à de Passo Fundo, como também à de Brasília, no caso de Maringá. Pela Tabela 1, pode-se verificar, para essas duas cultivares, que a semente do México apresentou valores de peso de mil sementes bastante superiores aos das outras origens, o que pode ter contribuído para essa vantagem inicial.

Tanto para stand quanto para peso de matéria seca, para as cultivares CNT 7, CNT 8, e CNT 10 não houve diferença entre sementes produzidas no México e em Passo Fundo.

$\mathrm{Na}$ avaliação do número de espigas por metro quadrado não foram observadas diferenças entre as origens das sementes (Tabela 2).

Para rendimento (Tabela 2), obteve-se resultado inferior para a semente da cultivar Nobre produzida no México em comparação com a semente 
produzida em Passo Fundo. Nos demais casos, as produções foram equivalentes para os dois locais, inclusive também para a origem Brasília, no caso de Maringá. Como os baixos rendimentos apresentados pela cultivar Nobre são devidos, em grande parte, a efeito de geada, é possível que esse fenômeno tenha influído na resposta apresentada. Também as cultivares CNT 7 e Maringá foram afetadas pela mesma geada, embora não tenham apresentado o mesmo comportamento de Nobre.

Apesar de não analisados estatisticamente, na Tabela 2 são apresentados os valores obtidos para o peso do hectolitro e peso de mil sementes das parcelas colhidas, observando-se, em alguns casos, pequenas variações.

Os resultados obtidos não corroboram observações anteriores no CNPT e resultados da OCEPAR (1976) quanto a um melhor desempenho de sementes de trigo produzidas no México em comparação com sementes produzidas no Brasil.

Além do problema de tipos de cultivares estudadas, é possível que o tratamento fungicida das sementes tenha contribuído para a não obtenção de respostas, o que estaria confirmando a suposição levantada pela OCEPAR (1976) e os resultados obtidos por Sterling et al. (1977).

\section{CONCLUSÃO}

Nas condições em que foi realizado o trabalho, de modo geral não houve superioridade das sementes de trigo produzidas no México em relação às produzidas no Brasil.

\section{AGRADECIMENTOS}

Os autores agradecem a valiosa colaboração prestada pelo Dr. Augusto C. Baier, na colheita e envio das sementes do México, ao Dr. Cantídio N.A. Sousa pelo mesmo trabalho com a semente de Brasília e ao Dr. João Carlos Ignaczak pela análise estatística dos dados.

\section{REFERÊNCIAS}

McNEAL, F.H.; BERG, M.A.; DUBBS, A.L.; KRALL, J.L.; BALDRIDGE, D.E.; HARTMAN, G.P. The evaluation of spring wheat seed from different sources. Agron. J., 52:303-304, 1960.

ORGANIZAÇÃO DAS COOPERATIVAS DO ESTADO DO PARANÁ. Relatório das atividades de pesquisa e experimentação - Trigo, s. I. 1976. n. p.

QUINBY, J.R.; REITZ, L.P.; LAUDE, H.H. Effect of source of seed on productivity of hard red winter wheat. Crop Sci., 2:201-203, 1962.

STERLING, J.D.E.; JOHNSTON, H.W.; MUNRO, D.C. Effects of seed source and seed treatment on barley emergence, yield, and kernel weight. Can. J. Plant Sci., 57:251-256, 1977. 